\section{Psychometric testing of immi- grants and natives in an acute psychiatry facility}

\author{
John E. Berg \\ Faculty of Health Sciences, Oslo and \\ Akershus University Hospital, Oslo, \\ Norway
}

\begin{abstract}
The diagnostic process after referral to an acute psychiatric treatment facility consists of more than the clinical investigation and laboratory tests. Psychometric tests in a broad range of languages may be such an augmentation of our diagnostic armamentarium. Whether such tests are in use, and how they are distributed among different patient categories was the aim of the study. All referrals in one calendar year $(\mathrm{N}=1168)$, as they are depicted in the hospital computerized medical records, were investigated. Fifty-six $(6.1 \%)$ out of 926 ethnic Norwegians and six $(3.0 \%)$ out of 198 nonWestern immigrants were tested, whereas none of the 44 Western immigrants. The difference between ethnic Norwegians and the immigrants was significant $(Z=-3.05$ and $\mathrm{P}=0.002$ ). Psychometric tests were thus almost not in use, and even lesser so in immigrants. Mean number of resident days was higher among those tested, 11.7 $(\mathrm{SD}=11.2)$ versus those not tested, 7.4 $(\mathrm{SD}=10.4)$ days, $\mathrm{t}=2.97$ and $\mathrm{P}=0.004$. Length of stay for ethnic Norwegians did not differ from that for non-Western immigrants 11.4 versus 11.7 , respectively. The patients tested were older than those not tested. Mean age was $43.0(\mathrm{SD}=14.4)$ versus $38.8(\mathrm{SD}=12.1)$, with a $\mathrm{t}=2.65$ and $\mathrm{P}=0.03$. The difference in resident days between all immigrants and ethnic Norwegians was significant with a $Z=$ = 2.232 and $\mathrm{P}=0.026$. Level of testing was higher in ethnic Norwegians, and the tested patients stayed longer, maybe indicating more room for testing. Whether this low test-activity influences treatment quality is an unsettled question.
\end{abstract}

\section{Introduction}

Acute psychiatric treatment is challenging. Decisions must be made under the pressure from patients, relatives and often policemen to start treatment. The initial judgments often must be made with little information other than the frail communication and behavior of the patient. If the patients come from cultural settings other than the local one, both obvious and subtle differences in behavior may be misinterpreted. Low literacy level may impinge on cognition and tests including cognitive tasks. This has been shown in elderly African Americans compared to elderly White Americans exhibiting racial differences in cognitive performance. ${ }^{1}$ Furthermore, reliable information from relatives may be lacking. All available sources for diagnostic information must thus be utilized, including tests that may enhance the empirical expertise of the acute care clinicians. Although initial diagnostic assessment may be difficult, patients admitted to an acute psychiatric department stay for a mean of 10 days. During this time, when the patients are not always preoccupied with ward program and have recovered somewhat from the initial confusion, free time to collaborate in testing should be available. Especially in patients with difficulties with oral communication, written and pictorial screening tools may apply to minimize the rate of incorrect diagnoses. Patients with posttraumatic stress were shown to have diverse clusters of symptoms according to their ethnicity in an US study. ${ }^{2}$ These differences extended also to depressive and dissociative symptoms. Swinson et al. studied patients admitted to emergency rooms in Toronto with panic attack. ${ }^{3}$ The diagnosis was confirmed with the Structured Clinical Interview for DSM-III (SCID). Patients receiving exposure instruction thereafter improved more than patients given reassurance. The Hospital anxiety and depression scale (HADS) was successfully used to indicate which patients in a chest pain emergency unit had anxiety and/or depression in need of psychiatric support. ${ }^{4}$ Patients having both a cardiac disease and anxiety, and those only having an anxiety condition, may get a targeted treatment, shortening unnecessary hospital days.

The mental health status of immigrants has been an ongoing topic of research in Norway. 5 Immigrants have the same frequency of referrals to an acute psychiatric facility as ethnic Norwegians, although the diagnostic pattern and degree of substance abuse differed, as shown in a former study. ${ }^{6}$ A systematic review of all papers 19902004 covering ethnicity and mental health indicated that the definition and operationalization of ethnic groups vary, and comparisons could be of little value for clinical settings. ${ }^{7}$

Saravay et al. investigated the relationship between psychological comorbidity and length of stay from a group of 424 patients admitted to a general hospital. ${ }^{8}$ They used several psychometric tests (Mini
Correspondence: John E. Berg, Oslo and Akershus University Hospital, Pilestredet 48. 0130 Oslo, Norway.

Tel.: +47.67235000.

E-mail: john@pong.no,john-erik.berg@hioa.no

Key words: Psychometric tests, ethnicity, acute ward.

Conflict of interest: the author declares no potential conflict of interest.

Received for publication: 22 November 2016. Revision received: 5 September 2017.

Accepted for publication: 5 September 2017.

This work is licensed under a Creative Commons Attribution-NonCommercial 4.0 International License (CC BY-NC 4.0).

C) Copyright J.E. Berg, 2017

Licensee PAGEPress, Italy

Mental Illness 2017; 9:6987

doi:10.4081/mi.2017.6987

Mental Status, Hopkins Symptom Checklist-90, Zung depression inventory) and found that psychiatric comorbidity increased length of stay. But the study material was not the result of routine use of psychometric tests. Both clinical judgments and computerized reading of psychometric tests have their pitfalls. ${ }^{9}$ Many clinicians seem to rely only on the former alternative.

A search of Pub Med using the following search items: psychometric tests, emergency psychiatry or acute psychiatry on a routine basis, did not disclose any articles from psychiatric departments. The articles found showed project based use of certain tests in medical emergency departments. There was also a near to complete paucity of articles covering the use of psychometric tests according to ethnicity.

The aim of the study was to investigate whether psychometric tests were used, as seen from the computerized medical records, and whether being an immigrant patient changed testing pattern.

\section{Materials and Methods}

All patients admitted to an acute psychiatric department during 2008, N=1168, were scrutinized as shown in the hospital computerized medical records. These records have a sub-item indicating the use of specified psychometric tests. The paper is based on these registrations. We did not know why specified psychometric tests were administered. Some tests are available in different languages, but for the patients 
from non-Western countries test items were translated by official interpreters used in communications with the patients. The computerized medical records did not give any indication of the reasons for using them. The author manually checked ethnicity (JEB). Resident days for each patient's stay runs from 0 , indicating that the patient was dismissed at the same day as he/she was remitted.

The immigrants included in this study were all first-generation immigrants. The official standard for immigrant classification in Norway defines first-generation immigrants as those who are born abroad and whose parents (both) are also born abroad. ${ }^{10}$ Ethnic Norwegians were defined as persons born in Norway to parents both being Norwegians. Non-Western immigrants were persons born to indigenous parents from Asia, Africa, Turkey and from the former Soviet Asian republics. Western immigrants were likewise defined as persons born to parents from Europe, including Ukraine, and Belarus, America, Australia and New Zealand.

The material has been extracted as part of the internal facility quality enhancement audit, and an ethics committee approval did not apply.

\section{Statistics}

Differences between groups were tested with non-parametric and parametric tests according to the distribution of the variables. Level of significance was set at $\mathrm{P}=0.05$ if not stated otherwise.

\section{Results}

The number of patients, in whom psychometric tests were used, was low (Table 1). Six percent of ethnic Norwegians were tested, and three percent of the non-Western immigrants. None of the Western immigrants were tested and this may reflect the lower number of Western immigrants referred to the ward and the overall rate of use of tests. The difference between ethnic Norwegians and the immigrants was significant, with Mann-Whitney test with $\mathrm{Z}=$ =3.05 and $\mathrm{P}=0.002$.

Mean number of resident days was higher among those tested, $11.7(\mathrm{SD}=11.2)$ versus $7.4(\mathrm{SD}=10.4)$ days, $\mathrm{t}=2.97$ and $\mathrm{P}=0.004$. There was no significant difference in length of stay among those tested between ethnic Norwegians and nonWestern immigrants, 11.4 versus 11.7 . None of the Western immigrants were tested. The patients tested were also older than those not tested. Mean age was $43.0(\mathrm{SD}=14.4)$ versus $38.8(\mathrm{SD}=12.1)$. The difference was significant at the level of $\mathrm{t}=2.65$ and $\mathrm{P}=0.03$. Number of resident days differed according to ethnicity (Table 2). Ethnic Norwegians had the longest mean stay, 7.9 $(\mathrm{SD}=11.0)$ days, whereas non-Western immigrants had the lowest $6.0(\mathrm{SD}=7.3)$ days and Western immigrants an intermediate mean stay of $7.1(\mathrm{SD}=11.0)$ days. The difference in resident days between all immigrants and ethnic Norwegians was significant with a Z-value $=-2.232$ and $\mathrm{P}=0.026$. There was no such difference between Western and non-Western immigrants, $\mathrm{Z}=-0.057$ and $\mathrm{P}=0.95$.

Mean age was $39.8(\mathrm{SD}=12.4) \quad 36.1$ $(\mathrm{SD}=11.1)$ and $34.9(\mathrm{SD}=11.3)$ for ethnic Norwegians, non-Western immigrants and Western immigrants, respectively. The difference between the two first categories was significant with a $\mathrm{t}=4.3$ and $\mathrm{P}=0.001$, and between first and third with a $\mathrm{t}=2.8$ and $\mathrm{P}=0.008$. There was no significant difference between the immigrant groups.

\section{Discussion and Conclusions}

The present study results were unexpected on two fronts.

Firstly, psychometric tests to purportedly increase diagnostic rigor, were used in far less than ten percent of patients. This is a nominator statement, as we do not know the level of the denominator. No studies have been found through Pub Med searches that report the use of psychometric tests on a routine basis in acute psychiatry departments. On the other hand comparisons have been made between clinical diagnosis in the acute care wards and structured interviews with SCID. 11 The study showed that less than half the cases agreed and even more so

Table 1. Number of tests performed according to ethnic background of all patients admitted to an acute psychiatric department in $2008, \mathrm{~N}=1168$.

\begin{tabular}{lcc}
\hline Ethnicity & Patients not tested & Patients tested, n (\%) \\
Ethnic Norwegians & 926 & $56(6.1)$ \\
Non-Western immigrants & 198 & $6(3.0)$ \\
\hline Western immigrants & 44 & $0(0.0)$ \\
\hline
\end{tabular}

Table 2. Number of resident days and mean age for patients admitted to an acute psychiatry department according to ethnicity.

\begin{tabular}{llccccc} 
Ethnicity & & N & Min & Max & Mean & SD \\
Ethnic & Resident days & 982 & 0 & 139 & 7.9 & 10.9 \\
Norwegians & Age & 982 & 19 & 89 & 39.8 & 12.4 \\
Non-Western & Resident days & 204 & 0 & 44 & 6.0 & 7.3 \\
immigrants & Age & 204 & 20 & 109 & 36.1 & 11.1 \\
\hline Western & Resident days & 44 & 0 & 45 & 7.1 & 10.7 \\
immigrants & Age & 44 & 21 & 61 & 34.9 & 11.3 \\
\hline
\end{tabular}

in non-White patients. This corroborates the purported added value of using such tests also in the acute ward, and especially in immigrant patients. Special units for instance for the young psychotic patients, do employ a battery of tests to certify a diagnosis of schizophrenia. ${ }^{12,13}$ The infrequent use of psychometric tests may hinge on one of the following factors:

i. Psychiatrists and doctors in training in psychiatry are unfamiliar with the tests. This may be remedied quickly as there are several useful questionnaires which the patient himself may fill in. Some examples are mentioned in Table 3.

ii. Psychologists are not employed in acute departments, or if so, do not want to perform tests. Some psychologists deplore being asked only to test patients with often elaborate tests as MMPI, SCID and Rorschack. Some tests demand authorization and have a price tag to the institution.

iii. The relative short stay of some patients. A quarter of the patients referred to our department are dismissed within 1-2 days, or the condition of the patient does not permit testing. Those who were tested had a longer stay in the present study.

iv. The responsible psychiatrist claim to know the patient so well that further differential diagnostic considerations are deemed superfluous. A post-hoc finding was that in such cases no testing was performed on earlier admissions either.

v. The tests are deemed not to give any view and ward observations. This is a short-sighted view which contrasts with the value given to tests in the scientific literature

The last point deserves some elaboramore information than the clinical inter- 
tion. Psychometric tests are thought to give added value above clinical judgments, although it might be important who helps the patient in filling in questionnaires. ${ }^{14-16}$ And this added value may be quantitatively compared between clinicians and used for national and even cross-cultural comparisons. But as far as we know, the usefulness of employing psychometric tests on a routine basis has not been shown in a randomized controlled study. And in many studies where the usefulness of psychometric tests is in focus, the authors seem to presuppose that the use has an inherent value. ${ }^{4,11}$ On the other hand, lack of correspondence between clinician-rated and patient-rated functioning has been studied. ${ }^{17}$ Diagnostic ideology is drifting over time, and psychiatrists changing work place report that the emphasis on diagnostic clarity may be different. Therefore, it is tempting to argue that the use of psychometric tests could be a second check of diagnostic drifting and differences in ideology in the specific wards.

Secondly, a difference or discrimination of immigrants could be shown regarding level of testing, even at the low rate of testing in the present study. The use of psychometric tests in different languages is a challenging task, which could reduce the probability of employing tests in other languages than the native Norwegian. Many tests do not exist in all the needed languages. Ad hoc translation of test questions by an interpreter could reduce the validity of the test. Also in the acute setting and with immigrants, all usual problems with psychometric testing occur. The predictive value of the test may be inadequate, especially after non-controlled translations. Some tests are not culturally neutral, as for instance AUDIT is deemed to be. But the clinical interview performed by one clinician may also be culturally colored, even when patient and health professional have a similar background.

A limitation of the present study is that the records do not give information on the circumstances of the testing procedure or the reasons given, if any, of the need to use tests. A prospective study would probably have increased the focus on testing and significantly changed the testing rate upward.

The computerized medical records of our hospital do not reveal the use of psychometric tests not scanned in by office clerks in the allotted sub-item. Some tests may have been missed. We had no way of checking the magnitude of this error, except reading through all the files. Point checking of a smaller number of files (20) did not reveal reporting of tests in the running text of the files not also filed in the sub-item.

Diagnostic accuracy in the acute setting is not always sufficient. A patient may arrive with a clinical picture indicating a schizoaffective disorder, an affective disorder or a borderline personality disorder, all or some contaminated with substance abuse. Tests as AUDIT, DUDIT, SCID or Personality Disorder Questionnaire may contribute to a better and quicker treatment decision. An initial clinical assessment may thus be augmented with separately gathered information independent of the individual clinician and her experience. Prodromal symptoms in young schizophrenics have been shown to be better evaluated using specifically developed questionnaires. ${ }^{12}$

Whether the use of psychometric tests improves treatment, is still an unsettled question. The study of Saravay et al. showed that depression and anxiety increased resident days, maybe as a sign of inefficient treatment resulting from a prolongation of a necessary diagnostic decision. Ehring et al. showed that not all psychometric tests for future posttraumatic stress disorder have a reasonable predictive value, although the use of the best tests improved the diagnostic accuracy. ${ }^{18}$ In a study of suicide attempters with and without borderline personality disorder, Berk et al. showed that the patients with borderline personality disorder displayed greater severity of overall psychopathology, depression, hopelessness and poorer social problem solving skills. ${ }^{19}$ Furthermore, the intent to die or lethality associated with the suicide attempt at admission to the acute facility, was not different. These findings were based on testing the patients in the first time at the acute ward with eight different tests. In a study from Toronto the authors explores the usefulness of clinical rating scales in the assessment of suicidal risk in an urban hospital, as the one in the present study. ${ }^{20}$ Based on their findings they do not recommend the use of six different scales prior to admission, as they did not predict suicide in single patients. For instance, hopelessness may not be an ideal indicator of suicide risk in the emergency setting because it is a predictor of suicide in the long run, i.e. more than a year. This fact has been shown by Beck et al. with his Hopelessness scale.21 From a sample of 1958 outpatients 16 of 17 eventually committing suicide had a cut-off score of 9 or above on this special test. Similar results have been demonstrated in a group of substance abusers exposed to the Antonovsky Sense of Coherence test.22,23 Even though these tests are not predictive of suicide in the emergency setting, they may be regarded as warning signs for the future follow up and rehabilitation of the patients and the test has been evaluated in different cultural and ethnic groups. Whether psychometric tests could improve diagnostic assessments in acute psychiatry, and how this should be promoted, merits further research. It raises a range of psychometric challenges to apply such tests to immigrant patients. If not addressed, these technical problems with tests would increase the rate of incorrect diagnoses where tests are not employed. The paucity of tests applied in our department is probably not well founded, but rather the result of the feeling of always having too much to do.

Table 3. List of tests employed.

\begin{tabular}{ll}
\hline Test name & Purported area of functioning tested \\
Antonovsky Sense of Coherence test (SOC) & Test of comprehensibility, manageability and meaning in life \\
AUDIT / DUDIT & Tests of alcohol and drug use patterns \\
\hline Beck depression Inventory (BDI) & Test of depressive traits \\
Clock test & One item test of dementia \\
\hline Hopkins symptom checklist (SCL-90) & Test of general psychiatric morbidity \\
\hline Hospital Anxiety Inventory (HAI) & Test of anxiety \\
\hline MADRS & Test of depression used mainly by GPs \\
Mini Mental Status (MMS) & Test of dementia \\
\hline MINI & Short test of psychiatric morbidity \\
\hline Positive and negative symptom schedule (PANSS) & Test of schizophrenia traits \\
\hline Young mania rating scale (YMRS) & Test of manic symptoms
\end{tabular}




\section{References}

1. Morgan AT, Marsiske M, Whitfield KE. Characterizing and explaining differences in cognitive test performance between African American and European American older adults. Exp Aging Res 2008;34:80-100.

2. Santos MR, Russo J, Aisenberg G, et al. Ethnic/racial diversity and posttraumatic distress in the acute care medical setting. Psychiatry 2008;71:234-45.

3. Swinson RP, Soulios C, Cox BJ, Kuch $\mathrm{K}$. Brief treatment of emergency room patients with panic attacks. Am J Psychiatry 1992;149:944-6.

4. Soares-Filho GL, Freire RC, Biancha $\mathrm{K}$, et al. Use of the Hospital anxiety and depression scale (HADS) in a cardiac emergency room: chest pain unit. Clinics 2009;64:209-14.

5. Iversen VC, Morken G. Acute admission among immigrants and asylum seekers to a psychiatric hospital in Norway. Soc Psychiatry Psychiatr Epidemiol 2003;38:515-9.

6. Berg JE, Johnsen E. Innlegges innvandrere oftere enn etniske nordmenn i akuttpsykiatriske avdelinger? Tidskr Nor Lægeforen 2004;124:634-6.

7. Møllersen S, Holte A. Ethnicity as a variable in mental health research: A systematic review of articles published 1990-2004. Nordic J Psychiatry 2008; 62:322-8.

8. Saravay SM, Steinberg MD, Weinschel B, et al., Psychological comorbidity and length of stay in the general hosptial. Am J Psychiatry 1991;148:324-9.

9. Lichtenberger E. Computer utilization and clinical judgment in psychological assessment reports. J Clin Psychol 2006;62:19-32.

10. Bjertnæs M. Immigration and immigrants 2000. Statistiscs Norway: Oslo; 2000. pp. 10-11.

11. Strakowski SM, Hawkins JM, Keck PE $\mathrm{Jr}$, et al. The effects of raceand information variance on disagreement between psychiatric emergencyservice and research diagnoses in first-epsidoe psychosis. J Clin Psychiatry 1997;58:45763.

12. Larsen TK, Johannessen JO, Opjordsmoen S. First-episode schizophrenia with long duration of untreated psychosis. Pathways to care. $\mathrm{Br} \mathrm{J}$ Psychiatr 1998;172:45-52.

13. Larsen TK, McGlashan TH, Johannessen JO, et al. Shortened duration of untreated first episode of psychosis: changes in patient characteristics at treatment. Am J Psychiatry 2001;158:1917-9.

14. Webster J, Hall L, Somville T, et al. Prospective testing of the Brisbane Postnatal Depression Index. Birth 2006;33:56-63.

15. Beals J, Novins DK, Spicer P, et al. Challenges in operationalizing the DSM-IV clinical significance criterion. Arch Gen Psychiatry 2004;61:1197207.

16. Antonovsky A. The structure and properties of the sense of coherence scale.
Soc Sci Med 1993;36:725-33.

17. Moritz S, Ferahli S, Nber D. Memory and attention performance in psychiatric patients: lack of correspondence between clinician-rated and patientrated functioning with neuropsychological test results. J Int Neuropsychological Soc 2004;10:62333.

18. Ehring T, Kleim B, Clark DM, et al., Screening for posttraumatic stress disorder. What combination of symptoms predicts best? J Nerv Ment Dis 2007;195:1004-12.

19. Berk MS, Jeglic E, Brown GK, et al. Characteristics of recent suicide attempters with and without borderline personality disorder. Arch Suicide Res 2007;11:91-104.

20. Cochrane-Brink KA, Lofchy JS, Sakinowsky I. Clinical rating scales in suicide risk assessment. Gen Hosp Psychiatry 2000;22:445-51.

21. Beck AT, Brown G, Berchick RJ, et al. Relationship between hopelessness and ultimate suicide: a replication with psychiatric outpatients. Am J Psychiatry 1990;147:190-5.

22. Berg JE, Andersen S. Mortality 5 years after detoxification and counselling as indicated by psychometric tests. Substance Abuse 2001;23:1-10.

23. Andersen S, Berg JE. The use of a sense of coherence test to predict drop-out and mortality after residential treatment of substance abuse. Addict Res Theory 2001;9:239-51. 